\title{
Sb nanoparticles encapsulated into porous carbon matrixes for high-performance lithium-ion
}

\section{battery anodes}

Zheng Yi, ${ }^{\mathrm{ab}}$ Qigang Han, ${ }^{\mathrm{ab} *}$ Ping Zan, ${ }^{\mathrm{a}}$ Yaoming $\mathrm{Wu}^{\mathrm{b}}$ Yong Cheng, ${ }^{\mathrm{b} * *}$ and Limin Wang ${ }^{\mathrm{b}}$

${ }^{\text {a }}$ College of Materials Science and Engineering, Jilin University, Changchun, 130025, China

${ }^{\mathrm{b}}$ State Key Laboratory of Rare Earth Resource Utilization, Changchun Institute of Applied Chemistry, CAS, Changchun 130022, China

*Corresponding author.

E-mail address: hanqg@jlu.edu.cn (Qigang Han). Fax: +86 43185094340.

E-mail address: cyong@ ciac.ac.cn (Yong Cheng). Fax: +86 43185262447.

Abstract: A novel Sb/C polyhedra composite is successfully fabricated by a galvanic replacement reaction technique using metal organic frameworks as templates. In this composite, the ultrasmall $\mathrm{Sb}$ nanoparticles with an average size of $15 \mathrm{~nm}$ are homogeneously encapsulated into the carbon matrixes, forming a hierarchical porous structure with nanosized building blocks. Used as an anode material for lithium ion batteries, this composite exhibits high lithium storage capacities, excellent rate capability and superior cycle stability, higher than many reported results. Notably, a discharge capacity of 565 $\mathrm{mAh} \mathrm{g}^{-1}$ at a current density of $0.2 \mathrm{~A} \mathrm{~g}^{-1}$ is delivered after 100 repeated cycles. Even at a high current density of $1 \mathrm{~A} \mathrm{~g}^{-1}$, a discharge capacity of $400.5 \mathrm{mAh} \mathrm{g}^{-1}$ is also maintained after 500 cycles. Such superior cycling stability and rate discharge performance of the designed $\mathrm{Sb} / \mathrm{C}$ composite can be attributed to the synergistic effect between $\mathrm{Sb}$ nanoparticles and the porous carbon matrixes.

Keywords: Lithium-ion batteries; Anode; Sb; Metal organic frameworks; Replacement reaction

\section{Introduction}

To circumvent the drawback of commercial graphite electrode for lithium-ion batteries (LIBs) with low theoretical specific capacity of $372 \mathrm{mAh} \mathrm{g}^{-1}$, new efforts have been focused on the metallic antimony (Sb) electrode owing to its high theoretical capacity of $660 \mathrm{mAh} \mathrm{g}^{-1}$ derived from the formation of a $\mathrm{Li}_{3} \mathrm{Sb}$ phase [1-3]. However, the severe volume expansion/contraction that accompanies the lithium insertion/extraction process leads to serious destruction of the electrode structure, and thus resulting in rapid capacity fading and deteriorative cycle lifetime. As a result, the practical application of Sb anode 
is seriously hindered by its poor capacity retention during cycling. Therefore, researchers never discontinuously do a task to remedy this limitation.

Several strategies are developed to overcome this challenge. Firstly, using $\mathrm{Sb}$-based alloy structure and inert metal matrix is considered to be a simple method. For instance, $\mathrm{Zn}_{4} \mathrm{Sb}_{3}$ nanotubes and $\mathrm{Mo}_{3} \mathrm{Sb}_{7}$ thin film are fabricated and applied as anode materials with enhanced cycling performances for LIBs [4-5]. Furthermore, porous structure is chose because of its superiority of the hollow core structure acted as buffer layers to retard volume changes and shorten lithium diffusion distance. J. Cho et al. and $\mathrm{X}$. Ji et al. have reported the advantages of Sb hollow nanospheres in lithium storage prepared by utilizing $\mathrm{SiO}_{2}$ and $\mathrm{Ni}$ nanosphere as templates, respectively [6-7]. As a promising strategy, the carbon materials have been widely introduced to fabricate the $\mathrm{Sb} / \mathrm{C}$ composite in which the carbon matrix can be acted as a barrier to accommodate volume expansion and restraint aggregation of active particles as well as increase the conductivity. For these technological superiorities, a large number of types of $\mathrm{Sb} / \mathrm{C}$ composites have been reported [8-12]. For example, rod-like $\mathrm{Sb} / \mathrm{C}$ composite has been prepared by $\mathrm{Y}$. Qian et al. via a synchronous reduction and carbon deposition process [11]. Y. Cao et al. have synthesized $\mathrm{Sb} / \mathrm{C}$ nanofibers through a single-nozzle electrospinning technique and subsequent calcination [9]. All the $\mathrm{Sb} / \mathrm{C}$ composites mentioned above exhibit enhanced electrochemical lithium storage performances in comparison with the corresponding bare metallic $\mathrm{Sb}$ anodes alone.

In this short communication, a new type of $\mathrm{Sb} / \mathrm{C}$ polyhedra composite is fabricated based on galvanic replacement reaction route employing the metal organic framework (MOF) as a template. It is well known that the zeolitic imidazolate framework (ZIF) is one of the MOF materials with the most simple synthesis method in indoor temperature. Furthermore, the connector (metal ion) of the ZIF-67 is $\mathrm{Co}^{2+}$, which can not only be easily reduced to Co only with the pyrolytic carbon as a reducing agent, but also have a lower electrode potential to offer a motivation to reduce the $\mathrm{Sb}^{3+}$. Hence, we choose the pyrolytic ZIF-67 as a template and a reducing agent for the replacement reaction from $\mathrm{Sb}^{3+}$ to $\mathrm{Sb}$, and then as a carbon matrix to assemble the reduced Sb nanoparticles. Because the Sb nanoparticles are in situ reduced and skillfully packaged in the interior of carbon matrix, the designed $\mathrm{Sb} / \mathrm{C}$ polyhedra composite has a good buffer effect to retard the volume change during lithium insertion/extraction process. Our results demonstrate that the $\mathrm{Sb} / \mathrm{C}$ polyhedra composite has better electrochemical 
performances. This work may enrich the preparation methods of $\mathrm{Sb} / \mathrm{C}$ composites and motivate further exploration for preparation of other metal/C composites for LIBs.

\section{Results and Discussion}

The strategy for synthesizing the $\mathrm{Sb} / \mathrm{C}$ composite is schematically depicted in Fig. 1. Firstly, the ZIF-67 is obtained as the precursor for fabricating the $\mathrm{Co} / \mathrm{C}$ composite. After a replacement reaction, the $\mathrm{Sb}$ nanoparticles in situ occupy the position of Co nanoparticles and then form the Sb/C polyhedra composite alliance. This design is aimed at obtaining the $\mathrm{Sb} / \mathrm{C}$ composite with cooperative advantages of synergistic effect between the Sb nanoparticle and the carbon matrix, as well as good buffer effect to retard volume changes during lithium insertion/extraction process. Based on these advantages, we attempt to improve the electrochemical cycling performance of the Sb/C composite for LIBs.

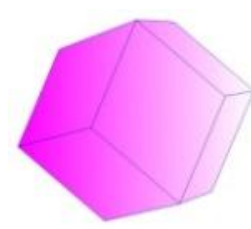

ZIF-67

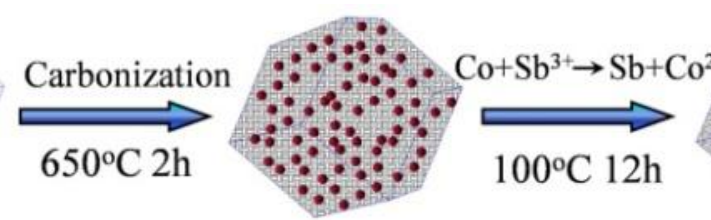

$\mathrm{Co} / \mathrm{C}$

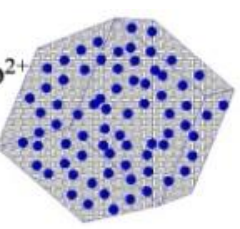

$\mathrm{Sb} / \mathrm{C}$

Fig. 1. Illustration of the synthesis route for $\mathrm{Sb} / \mathrm{C}$ composite.

The X-ray diffraction (XRD) pattern of the ZIF-67 precursor is shown in Fig. S1 (Supporting Information). It can be seen that all diffraction peaks with strong intensities match well with the simulated ZIF-67 [13-15], indicating the pure phase and high crystallinity of the ZIF-67 precursor. The representative scanning electron microscope (SEM) image of ZIF-67 precursor is presented in Fig. S2 (Supporting Information), which exhibits that the ZIF-67 precursor composes of uniform rhombic dodecahedron particles with a size of approximately $300 \mathrm{~nm}$ and a perfectly smooth surface.

Pyrolysis of $\mathrm{ZIF}-67$ precursor at $650^{\circ} \mathrm{C}$ for $2 \mathrm{~h}$ under $\mathrm{Ar}$ atmosphere gains the $\mathrm{Co} / \mathrm{C}$ composite. The XRD pattern of the $\mathrm{Co} / \mathrm{C}$ composite (Fig.2a) presents that all diffraction peaks agree well with the metallic Co (JCPDS 15-0806). From the SEM image as shown in Fig. 2b, it is clearly observed that the 
$\mathrm{Co} / \mathrm{C}$ composite retains the pristine rhombic dodecahedron structure. A small number of carbon nanotubes are discovered on the surface of the polyhedra, which can be attributed to the catalytic action of Co nanoparticles in the pyrolysis process [16]. The transmission electron microscopy (TEM) image (Fig.2c) reveals that the Co nanoparticles are uniformly distributed in the carbon matrix. To further confirm the morphology features of the Co/C composite, high-resolution TEM (HRTEM) is used. As shown in Fig.2d, the grain size of the Co nanoparticle is approximately $10 \mathrm{~nm}$. The measured $\mathrm{d}$-spacing of the selected nanoparticle is $0.205 \mathrm{~nm}$, which corresponds well to the (111) plane of Co. Notedly, the $\mathrm{Co} / \mathrm{C}$ composite is successfully prepared as a template to further fabricate the $\mathrm{Sb} / \mathrm{C}$ composite.


Fig. 2. (a) XRD pattern, (b) SEM image, (c) TEM image and (d) HRTEM image of the Co/C composite.

The $\mathrm{Sb} / \mathrm{C}$ composite is fabricated by a replacement reaction between $\mathrm{Sb}^{3+}\left(\mathrm{E}^{\Theta}\left(\mathrm{Sb}^{3+} / \mathrm{Sb}\right)=0.241 \mathrm{~V} v s\right.$. standard hydrogen electrode $(\mathrm{SHE}))$ and $\mathrm{Co}\left(\mathrm{E}^{\Theta}\left(\mathrm{Co}^{2+} / \mathrm{Co}\right)=-0.28 \mathrm{~V}\right.$ vs. SHE). Fig. 3a shows the XRD result of as-prepared $\mathrm{Sb} / \mathrm{C}$ composite, in which the sharp peaks correspond to metallic Sb (JCPDS 35-3732). The XRD result effectively certifies the successful replacement reaction process occurs between $\mathrm{Sb}^{3+}$ and Co. A calculation using Scherrer's equation indicates an equivalent particle size of $16.8 \mathrm{~nm}$, as to be shown below, which is consistent with the TEM result [17]. The TEM image (Fig.3b) and the SEM images (Fig. S3a-b, Supporting Information) reveal that the as-prepared Sb/C composite 
nearly maintains the ideal polyhedra structure inherited from its precursor. Furthermore, it also presents that the $\mathrm{Sb}$ nanoparticles with typical grain size of approximately $15 \mathrm{~nm}$ are well-dispersed in the carbon matrix. As shown in Fig.3c, the lattice spacing of $0.215 \mathrm{~nm}$ and $0.225 \mathrm{~nm}$ can be assigned to (110) and (104) plane of Sb phase, respectively, which confirms the in situ transformation of Co to Sb in the replacement reaction process. The highly distributed structure of $\mathrm{Sb} / \mathrm{C}$ composite is also proven by the uniform distribution of $\mathrm{C}, \mathrm{N}$ and Sb elements from $\mathrm{X}$-ray spectroscopy (EDS) mapping (Fig.3d). It can be seen that those elements are uniform dispersed and coexisted over a whole polyhedral unit. The thermogravimetric (TG) curve (Fig. S4a, Supporting Information) is conducted to determine the actual contents of $\mathrm{Sb}$ and $\mathrm{C}$ in the $\mathrm{Sb} / \mathrm{C}$ composite. Based on the weight loss of carbon combustion and the weight gain of $\mathrm{Sb}_{2} \mathrm{O}_{4}$ formation (confirmed by the XRD pattern as shown in Fig. S4b, Supporting Information), the actual Sb content in the composite is calculated to be 52.17 wt. $\%$.
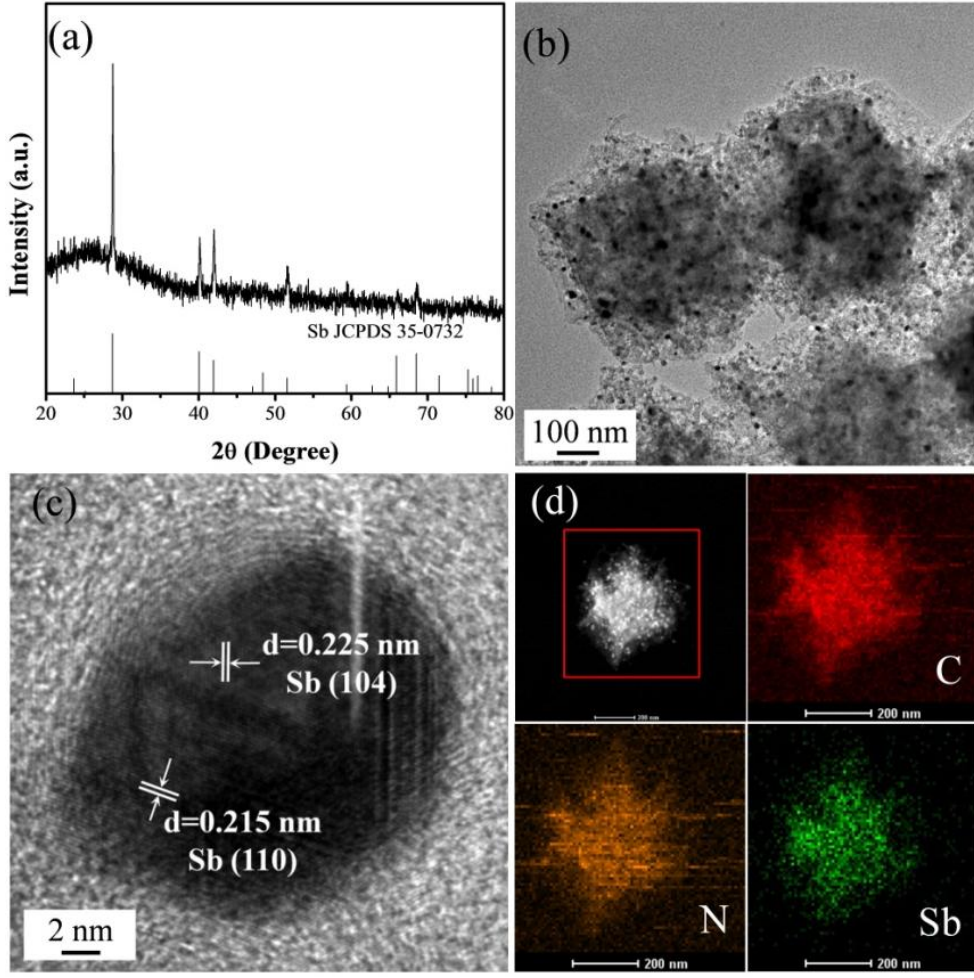

Fig. 3. (a) XRD pattern, (b) TEM image, (c) HRTEM image and (d) EDS mapping of the Sb/C composite.

To further determine the chemical compositions of as-prepared $\mathrm{Co} / \mathrm{C}$ and $\mathrm{Sb} / \mathrm{C}$ composites, $\mathrm{X}$-ray 
photoelectron spectrometry (XPS) is carried out. The survey spectra and the high-resolution Co $2 \mathrm{p}$ orbital regions of the obtained $\mathrm{Co} / \mathrm{C}$ and $\mathrm{Sb} / \mathrm{C}$ composites are displayed in Fig. S5a-b (Supporting Information). It can be obviously noted that the characteristic peaks of Co exist in $\mathrm{Co} / \mathrm{C}$ composite, but disappear in the $\mathrm{Sb} / \mathrm{C}$ composite, which intensely prove our experimental design that the $\mathrm{Co}$ nanoparticles in the carbon matrix can be in situ replaced by $\mathrm{Sb}^{3+}$ to form the $\mathrm{Sb} / \mathrm{C}$ composite. The above analyses suggest that a $\mathrm{Sb} / \mathrm{C}$ polyhedra composite is successfully obtained in this replacement reaction method by employing the metal organic framework as a template.

To study the porous property of the $\mathrm{Sb} / \mathrm{C}$ composite, $\mathrm{N}_{2}$ adsorption-desorption and the corresponding pore size distribution curve are conducted. As shown in Fig. S6a (Supporting Information), the $\mathrm{N}_{2}$ adsorption-desorption isotherm can be classified as a typical IV $\left(\mathrm{H}_{3}\right)$ isotherm with a distinct hysteresis loop, indicating the presence of distinct mesoporous microstructure. The BET surface areas and the total pore volume are $322.5 \mathrm{~m}^{2} \mathrm{~g}^{-1}$ and $0.2016 \mathrm{~cm}^{3} \mathrm{~g}^{-1}\left(\mathrm{P} / \mathrm{P}_{0}=0.9718\right)$, respectively. A narrow pore-size distribution (Fig.S6b, Supporting Information) in the range of $1.7-5 \mathrm{~nm}$ and an average pore size of 2.5 $\mathrm{nm}$ of the $\mathrm{Sb} / \mathrm{C}$ composite are calculated according to the desorption data using Barrett-Joyner-Halenda (BJH) model. The large surface areas can endow the $\mathrm{Sb} / \mathrm{C}$ composite with large electrode-electrolyte contact area and more lithium storage sites. Meanwhile, the hierarchical porous characteristic can contribute to relieve the mechanical stress caused by volume change during cycling, thus enhancing the electrochemical performance of the composite for LIBs.

After its structure and morphology representation, the lithium storage performances of as-prepared $\mathrm{Sb} / \mathrm{C}$ composite are evaluated by cyclic voltammetry (CV) and charge-discharge cycling. The CV curves of first two cycles at a scan rate of $0.1 \mathrm{mV} \mathrm{s}^{-1}$ are presented in Fig. 4a. In the first cathodic sweep, a broad cathodic peak around $0.6 \mathrm{~V}$ is attributed to the lithiation reaction from $\mathrm{Sb}_{\text {to }} \mathrm{Li}_{3} \mathrm{Sb}$ at the beginning and the subsequent formation of solid electrolyte interphase (SEI) film $[8,18]$. It doesn't appear in the second cycle, reflecting the stable property of SEI film in the first cycle. This cathodic peak is replaced by the sharp peak located at $0.8 \mathrm{~V}$ in following cycles, which is ascribed to the reaction of metallic $\mathrm{Sb}$ to alloyed $\mathrm{Li}_{3} \mathrm{Sb}$ [19]. During the anodic process, the peak located at about 1.16 $\mathrm{V}$ corresponds to delithiation reactions of $\mathrm{Li}_{3} \mathrm{Sb}$ to return to metallic $\mathrm{Sb}[20,21]$. 
Fig.4b shows the initial two charge and discharge curves of the $\mathrm{Sb} / \mathrm{C}$ composite measured between 0.01 and $2.0 \mathrm{~V}$ at a current density of $1 \mathrm{~A} \mathrm{~g}^{-1}$. There is a voltage plateau at $0.82 \mathrm{~V}$ in the discharge curves, which corresponds to the formation of a $\mathrm{Li}_{3} \mathrm{Sb}$ phase in the lithium insertion process. The voltage plateaus around $1.07 \mathrm{~V}$ in the charge curves are ascribed to the lithium exsertion reaction from alloyed $\mathrm{Li}_{3} \mathrm{Sb}$ phase. All the voltage plateaus in the discharge and charge curves (Fig.4b) agree well with the cathodic and anodic peaks in the CV curves (Fig.4a), respectively. Due to the lower lithium insertion potential, the capacitive contribution from the porous carbon component leads to more slow voltage drop under $0.82 \mathrm{~V}$ in discharge at a wide potential window. The first discharge and charge capacities of the $\mathrm{Sb} / \mathrm{C}$ composite are 896.9 and $457.4 \mathrm{mAh} \mathrm{g}^{-1}$ based on the total mass of the composite at a current density of $1 \mathrm{~A} \mathrm{~g}^{-1}$. The large initial capacity loss may be partly attributed to the formation of a thick SEI layer on the electrode surface during the first discharge step and the storage of lithium ion in nanoporous voids, which are difficult to be extracted [22].

The cycling behaviours of the $\mathrm{Sb} / \mathrm{C}$ composite at a current density of $0.2 \mathrm{~A} \mathrm{~g}^{-1}$ are shown in Fig.4c. After the first cycle, the discharge capacity decays to $617 \mathrm{mAh} \mathrm{g}^{-1}$ and a high reversible discharge capacity of $565 \mathrm{mAh} \mathrm{g}^{-1}$ is retained with high coulombic efficiencies after 100 cycles. The rate discharge ability of $\mathrm{Sb} / \mathrm{C}$ composite is investigated at various current densities ranging from 0.2 to $5 \mathrm{~A}$ $\mathrm{g}^{-1}$. As presented in Fig.4d, the $\mathrm{Sb} / \mathrm{C}$ composite electrode shows decent capacity retention with average discharge capacities of 582.7, 548.7, and $502.6 \mathrm{mAh} \mathrm{g}^{-1}$ at different current densities of $0.2,0.5$, and 1 $\mathrm{A} \mathrm{g}^{-1}$, separately. Even at the high current density of 2 and $5 \mathrm{~A} \mathrm{~g}^{-1}$, average discharge capacities of 437.1 and $315.4 \mathrm{mAh} \mathrm{g}^{-1}$ can still be delivered. Moreover, when the current density goes back to $0.2 \mathrm{~A}$ $\mathrm{g}^{-1}$, the specific discharge capacity can return and maintain at the value of $523.1 \mathrm{mAh} \mathrm{g}^{-1}$ after 70 cycles. These results indicate the electrode is stable and has high reversibility. Moreover, the rate discharge ability of the $\mathrm{Sb} / \mathrm{C}$ composite is also investigated at a continuous current density of $1 \mathrm{~A} \mathrm{~g}^{-1}$ to 500 repeated cycles. As shown in Fig.4e, $400.5 \mathrm{mAh} \mathrm{g}^{-1}$ can also be obtained even at this higher condition. 

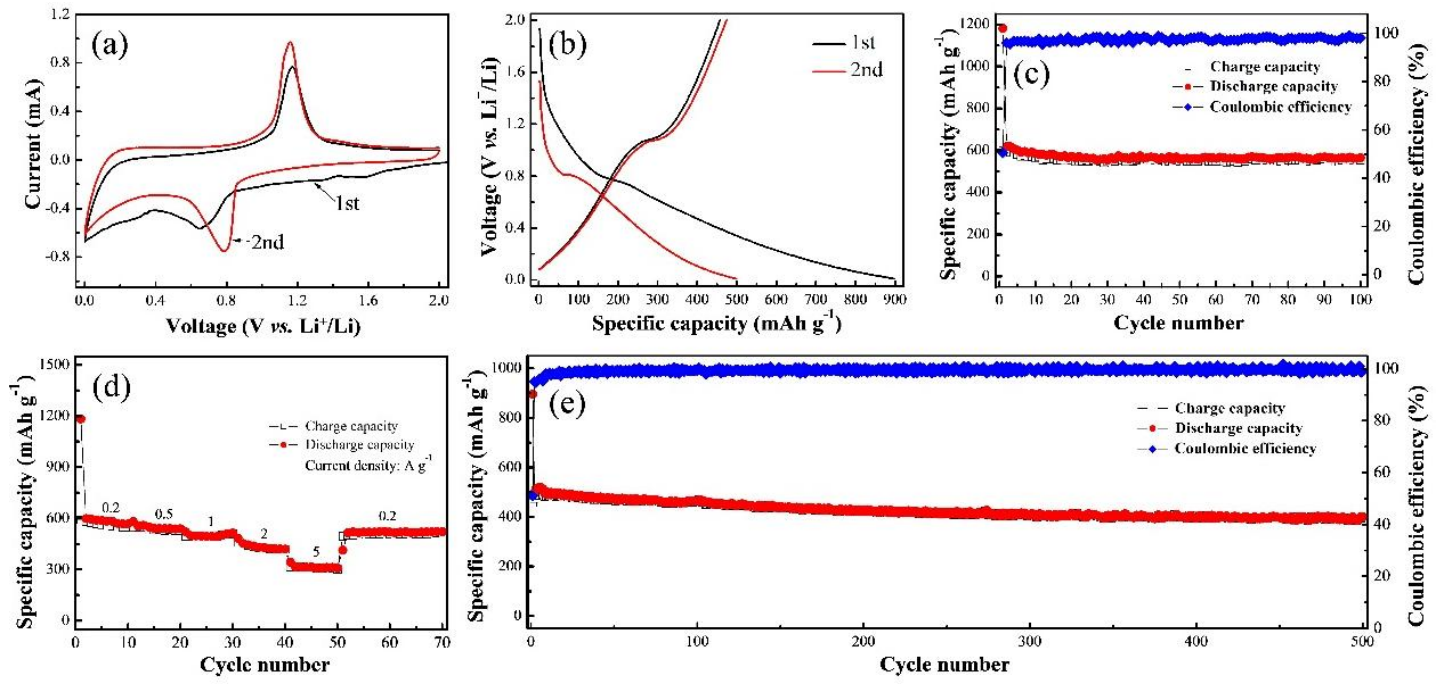

Fig. 4. (a) CV curves, (b) Voltage-Capacity curves, (c) galvanostatic discharge-charge cycles at a current density of $0.2 \mathrm{~A} \mathrm{~g}^{-1}$, (d) rate discharge-charge performance from 0.2 to $5 \mathrm{~A} \mathrm{~g}^{-1}$ and (e) galvanostatic discharge-charge cycles at a current density of $1 \mathrm{~A} \mathrm{~g}^{-1}$ of $\mathrm{Sb} / \mathrm{C}$ composite.

Table 1. Comparison of the electrochemical performances of the prepared $\mathrm{Sb} / \mathrm{C}$ composites with previously reported $\mathrm{Sb}-\mathrm{C}$-based composites.

\begin{tabular}{|c|c|c|c|c|}
\hline Materials & $\begin{array}{c}\text { Current } \\
\left(\mathbf{A ~ g ~}^{-1}\right)\end{array}$ & $\begin{array}{c}\text { Cycle } \\
\text { numbers }\end{array}$ & $\begin{array}{l}\text { Capacity } \\
\left(\mathrm{mAh} \mathrm{g}^{-1}\right)\end{array}$ & References \\
\hline $\mathrm{Sb}-\mathrm{CNT}$ & 0.05 & 30 & 287 & 23 \\
\hline $\mathrm{Sb}-\mathrm{C}$ & 0.3 & 20 & 408 & 24 \\
\hline \multirow{2}{*}{ Sb-carbon } & 0.23 & 250 & 550 & \multirow{2}{*}{25} \\
\hline & 1.15 & - & 400 & \\
\hline $\mathrm{Sb} / \mathrm{CNT}$ & 0.25 & 50 & 277.4 & 26 \\
\hline \multirow{2}{*}{ Antimony/carbon } & 0.1 & 100 & 315.9 & \multirow{2}{*}{8} \\
\hline & 0.8 & - & 246.2 & \\
\hline \multirow{2}{*}{ Sb-C } & 0.1 & 100 & 478.8 & \multirow{2}{*}{11} \\
\hline & 0.5 & - & 369.7 & \\
\hline \multirow{2}{*}{ Sb-Graphene } & 0.1 & 50 & 424.1 & \multirow{2}{*}{27} \\
\hline & 1 & - & 158 & \\
\hline \multirow{3}{*}{$\mathrm{Sb} / \mathrm{C}$ composite } & 0.2 & 100 & 565 & \multirow{3}{*}{ This work } \\
\hline & 1 & 500 & 400.5 & \\
\hline & 5 & - & 315.4 & \\
\hline
\end{tabular}

Combined with the above results, it can be seen that the $\mathrm{Sb} / \mathrm{C}$ composite exhibits splendid electrochemical performance, which is larger than that of many reported Sb-C-based anode materials for LIBs, as listed in Table 1 [8, 11, 23-27]. In consideration of the comparable electrochemical 
performance, the obtained $\mathrm{Sb} / \mathrm{C}$ composite is more suitable as an anode material for future LIBs. On the basis of the above results, the enhanced electrochemical performance of the $\mathrm{Sb} / \mathrm{C}$ composite can be attributed to the synergistic effect between $\mathrm{Sb}$ nanoparticles and the carbon matrix. Firstly, the in situ formed $\mathrm{Sb}$ nanoparticles possess ultrasmall and uniform size to accommodate structural stress. Secondly, the carbon matrix can prevent the $\mathrm{Sb}$ nanoparticles from aggregating into bulk particles not only in the preparation process but also in the charge-discharge process. Thirdly, the carbon matrix has advantages to improve electrochemical performances due to its excellent buffer effect to retard volume change during repeated cycles. Fourthly, the high electrical conductivity of carbon matrix can contribute to improved rate capability of the composite. Lastly, the porous structure provides abundant channels for electrolyte penetration and extra additional space to relax the stress and alleviate the structure decomposition induced by lithium ion insertion/extraction.

\section{Conclusions}

In summary, a porous $\mathrm{Sb} / \mathrm{C}$ polyhedra composite has been successfully prepared by a facile galvanic replacement reaction route employing metal organic framework as a template. In this composite, the ultrasmall $\mathrm{Sb}$ nanoparticles with an average size of $15 \mathrm{~nm}$ are homogeneously encapsulated into carbon matrix, forming a hierarchical porous structure with nanosized building blocks. Based on its structural advantage, the $\mathrm{Sb} / \mathrm{C}$ polyhedra composite exhibits enhanced cycling stability and good rate discharge ability. On account of the advantages of preparation methods and electrochemical performances, the porous $\mathrm{Sb} / \mathrm{C}$ polyhedra composite is considered as one of promising candidate anode materials for future LIBs. Our work presents a facile strategy to fabricate the hierarchical porous composite, which can motivate further exploration for preparation other metal-carbon composites in the field of energy storage and electrical devices.

\section{Acknowledgements}

This work is supported by the National Science Foundation of China (Project No. 51475207), and the

China Postdoctoral Science Foundation (Grant No. 2015m580253). 


\section{References}

1 M. N. Obrovac and V. L. Chevrier, Chem. Rev., 2015, 115, 2043-2043.

2 C. M. Park, J. H. Kim, H. Kim and H. J. Sohn, Chem. Soc. Rev., 2010, 39, 3115-3141.

3 M. He, K. Kraychyk, M. Walter and M. V. Kovalenko, Nano lett., 2014, 14, 1255-1262.

4 J. J. Xu, H. Y. Wu, F. Wang, Y. Y. Xia and G. F. Zheng, Adv. Energy Mater., 2013, 3, 286-289.

5 L. Baggetto, E. Allcorn, R. R. Unocic, A. Manthiram and G. M. Veith, J. Mater. Chem. A, 2013, 1, $11163-11169$.

6 H. Kim and J. Cho, Chem. Mater., 2008, 20, 1679-1681.

7 H. S. Hou, M. J. Jing, Y. C. Yang, Y. R. Zhu, L. B. Fang, W. X. Song, C. C. Pan, X. M. Yang and X. B. Ji, ACS applied mater.interfaces, 2014, 6, 16189-16196.

8 H. L. Lv, S. Qiu, G. X. Lu, Y. Fu, X. Y. Li, C. X. Hu and J. R. Liu, Electrochim. Acta, 2015, 151, $214-221$.

9 L. Wu, X. H. Hu, J. F. Qian, F. Pei, F. Y. Wu, R. J. Mao, X. P. Ai, H. X. Yang and Y. L. Cao, Energ. Environ. Sci., 2014, 7, 323-328.

10 W. Luo, S. Lorger, B. Wang, C. Bommier and X. L. Ji, Chem. Commun., 2014, 50, 5435-5437.

11 L. Fan, J. J. Zhang, J. H. Cui, Y. C. Zhu, J. W. Liang, L. L. Wang and Y. T. Qian, J. Mater. Chem. A, 2015, 3, 3276-3280.

12 X. S. Zhou, Z. H. Dai, J. C. Bao and Y. G. Guo, J. Mater. Chem. A, 2013, 1, 13727-13731.

13 Q. F. Wang, R. Q. Zou, W. Xia, J. Ma, B. Qiu, A. Mahmood, R. Zhao, Y. Y. C. Yang, D. G. Xia and Q. Xu, Small, 2015, 11, 2511-2517.

14 R. B. Wu, X. K. Qian, X. H. Rui, H. Liu, B. L. Yadian, K. Zhou, J. Wei, Q. Y. Yan, X. Q. Feng, Y. Long, L. Y. Wang and Y. Z. Huang, Small, 2014, 10, 1932-1938.

15 J. Yang, F. J. Zhang, H. Y. Lu, X. Hong, H. L. Jiang, Y. Wu and Y. D. Li, Angew. Chem. Int. Edit., 2015, 54, 10889-10893.

16 R. B. Wu, D. P. Wang, X. H. Rui, B. Liu, K. Zhou, A. W. K. Law, Q. Y. Yan, J. Wei and Z. Chen, Adv. Mater., 2015, 27, 3038-3044.

17 H. Kim, D. H. Seo, S. W. Kim, J. Kim, K. Kang, Carbon, 2015, 49, 326-332.

18 A. Dailly, J. Ghanbaja, P. Willmann and D. Billaud, Electrochim. Acta, 2003, 48, 977-984. 
19 J. X. Zhu, T. Sun, J. S. Chen, W. H. Shi, X. J. Zhang, X. W. Lou, S. Mhaisalkar, H. H. Hng, F. Boey, J. Ma and Q. Y. Yan, Chem. Mater., 2010, 22, 5333-5339.

20 D. H. Chang, H. Huo, K. E. Johnston, M. Menetrier, L. Monconduit, C. P. Grey and A. Van der Ven, J. Mater. Chem. A, 2015, 3, 18928-18943.

21 Y. C. Yang, X. M. Yang, Y. Zhang, H. S. Hou, M. J. Jing, Y. R. Zhu, L. B. Fang, Q. Y. Chen and X. B. Ji, J. Power Sources, 2015, 282, 358-367.

22 J. Liu, Y. R. Wen, P. A. van Aken, J. Maier and Y. Yu, Nano lett., 2014, 14, 6387-6392.

23 W. X. Chen, J. Y. Lee and Z. L. Liu, Carbon,2003, 41, 959-966.

24 X. M. He, W. H. Pu, L. Wang, J. G. Ren, C. Y. Jiang and C. R. Wan, ElectrochimicaActa, $2007,52,3651-3653$.

25 T. Ramireddy, M. M. Rahman, T. Xing, Y. Chen and A. M. Glushenkov, J. Mater. Chem. A, 2014, 2, 4282-4291.

26 Y. N. NuLi, J. Yang and M. S. Jiang, Materials Letters, 2008,62, 2092-2095.

27 Z. Yi, Q. G. Han, Y. Cheng, F. X. Wang, Y. M. Wu and L. M. Wang, ElectrochimicaActa, $2016,190,804-810$

\section{Figure Captions}

Fig. 1. Illustration of the synthesis route for $\mathrm{Sb} / \mathrm{C}$ composite.

Fig. 2. (a) XRD pattern, (b) SEM image, (c) TEM image and (d) HRTEM image of the Co/C composite.

Fig. 3. (a) XRD pattern, (b) TEM image, (c) HRTEM image and (d) EDS mapping of the Sb/C composite.

Fig. 4. (a) CV curves, (b) Voltage-Capacity curves, (c) galvanostatic discharge-charge cycles at a current density of $0.2 \mathrm{~A} \mathrm{~g} \mathrm{~g}^{-1}$, (d) rate discharge-charge performance from 0.2 to $5 \mathrm{~A} \mathrm{~g}^{-1}$ and (e) galvanostatic discharge-charge cycles at a current density of $1 \mathrm{~A} \mathrm{~g}^{-1}$ of $\mathrm{Sb} / \mathrm{C}$ composite.

\section{Table List}

Table 1 Comparison of the electrochemical performances of the prepared $\mathrm{Sb} / \mathrm{C}$ composites with previously reported Sb-C-based composites. 


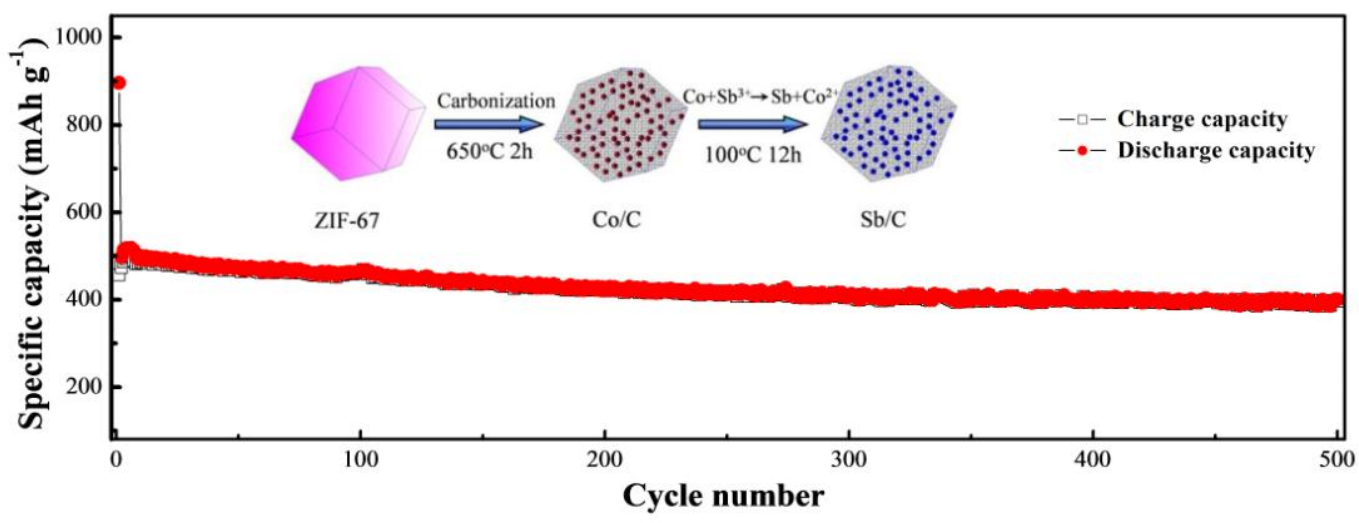

